\title{
Study of Antioxidant Properties in Black Tea and Green Tea
}

\author{
Kiran $^{1 *}$ and Pradeep Kumar ${ }^{2}$ \\ ${ }^{1}$ Department of Biochemistry, Dr Rajendra Prasad Central Agricultural University, Pusa, \\ Samastipur (Bihar) - 848125, India \\ ${ }^{2}$ Department of Agricultural Biotechnology and Molecular Biology, Dr Rajendra Prasad \\ Central Agricultural University, Pusa, Samastipur(Bihar) - 848125, India \\ *Corresponding author
}

\section{A B S T R A C T}

\begin{tabular}{|l|}
\hline K e y w or d s \\
$\begin{array}{l}\text { Green tea, Black } \\
\text { tea, TPC, Total } \\
\text { antioxidant, FRAP } \\
\text { activity }\end{array}$ \\
\hline Article Info \\
\hline $\begin{array}{l}\text { Accepted: } \\
\text { 10 April } 2018 \\
\text { Available Online: } \\
\text { 10 May } 2018\end{array}$ \\
\hline
\end{tabular}

The present study was conducted to assess and compare the total polyphenol content (TPC), antioxidant activity in black and green tea. The green tea showed a higher polyphenol content and antioxidant levels than black tea $(\mathrm{p}<0.05)$. The variations in polyphenolic levels in black tea (2.11- $0.26 \mathrm{mg} \mathrm{TAE} / \mathrm{g})$ and green tea $(5.20-1.17 \mathrm{mg}$ $\mathrm{TAE} / \mathrm{g}$ ) observed in our study. In black tea, the FRAP levels ranged from (5.58 $\mathrm{mg} \mathrm{AAE} / \mathrm{g}$ to $1.21 \mathrm{mg} \mathrm{AAE} / \mathrm{g}$ ) whereas in green tea has ranged (8.88 mg AAE/g to $3.26 \mathrm{mg} \mathrm{AAE} / \mathrm{g}$. The total antioxidant capacity in green tea $(22.866 \pm 7.036 \mathrm{mg} \mathrm{AAE} / \mathrm{g})$ is significantly higher than in black tea $(3.386 \pm 1.28 \mathrm{mg} \mathrm{AAE} / \mathrm{g})$. The activities of antioxidant were well correlated the total polyphenol content $\mathrm{r} 2=0.9571$ for FRAP method and $\mathrm{r} 2=0.9287$ for Polymolybdenum assay. The Assam and Darjeeling green tea (North East India) had higher TPC and antioxidant levels than Munnar, Coimbatore Nilgiri green tea (south India). However, the more studies on Indian tea to emphasize the health benefits of Indian tea especially green tea which will help in its increased consumption as a favorite beverage in India.

\section{Introduction}

Tea is one of the most widely consumed beverages in the world, next to water (Cheng, 2004 and Vinson, 2000) with a per capita consumption of $\sim 120 \mathrm{~mL} /$ day (Mckay, et al., 2002). This popularity is probably related with its sensorial properties, relatively low retail price, stimulating effects and potential health benefits (Baptista et al., 1998 and Baptista, et al., 1999). The biological properties of tea include effects on the Central System (CNS) and antioxidant effects, attributed to the presence of methylxanthines, such as caffeine and phenolic compounds, especially catechins (Shagana, et al., 2017). Tea after processed, which is one of the most popular beverages, is manufactured from the young tender leaves of the plant Camellia sinensis (Cabrera et al., 2003). Tea is derived from terminal leaves of shoots of tea plant Camellia sinensis family. Sinensis species is divided into two distinct varieties sinensis and assamica. Camellia sinensis var. sinensis is indigenous to South east China, Darjeeling, Japan. Camellia sinensis var assamica is indigenous to Assam, 
Thailand, Sri Lanka (Macfarlane et al., 2004). There are mainly three types of Camellia tea which are Green, Oolong and Black tea. The difference lies in the 'fermentation' which refers to oxidative and enzymatic changes within the tea leaves during processing (Hicks, 2001). Worldwide, the consumer's preference is approximately $76-78 \%$ of black tea followed by green tea (20-22\%) and oolong tea $(2 \%)$. The bulk of tea is produced in the Northeast (West Bengal and Assam), followed by the Northern area (Himachal Pradesh) and small quantities are produced in the Southern India (Tamilnadu) tea followed by green tea $(20-22 \%)$ and oolong tea (2\%). Tea from Darjeeling, Assam, and Nilgiri are world famous for their taste and flavor. In contrast, during black tea processing, tea shoots are macerated to initiate oxidation by polyphenol oxidase (PPO) before firing. TFs (Theaflavins) are also present in tea which gives a yellowred coloration in fermented black tea and contributes to the briskness and brightness of tea liquor. The manufacturing method for semi-fermented oolong tea consists of solar withering, panning, rolling and drying. Throught this process, the characteristic floral aroma of oolong tea is produced. White tea may be a rare specialty tea that gets its name from a paricular tea plant variety selection as well as a selected post-harvest processing technique that raises small silvery hairs on the dried buds. The differencesbetween the various processes of manufacture result in differences in the polyphenol profile between green, black, oolong and white tea.

The chemical composition of tea is complex and includes alkaloids (caffeine, theophylline, and theobromine), polyphenols, carbohydrates, amino acids, proteins, volatile compounds, minerals, chlorophyll, trace elements and other unidentified compounds. Among these, polyphenols constitute the most interesting group and are the main bioactive molecules in tea (Cabrera et al., 2003). The major polyphenolic compounds in tea are the flavan-3-ols called catechine (Peterson et al., 2005). Catechins account for $6-16 \%$ of the dry green tea leaves. When the black tea is oxidized, the catechins are converted into theaflavins and thearubigins which still act as antioxidants (Ho et al., 1994). The theaflavins and thearubigins are sometimes called tannins and are responsible for the darker color of black tea and more heavily-oxidized oolong teas (Wang et al., 2001). Green tea is rich in chemicals called catechins which are a form of flavanol monomers, a type of flavonoid. The catechins include epicatechin (EC), epigallocatechin (EGC), epicatechin-3- gallate (ECG), and epigallocatechin-3-gallate (EGCG). Green tea also contains a little amount of an antioxidant, Vitamin $\mathrm{C}$, which is also an essential nutrient (Farhoosh et al., 2007). Polyphenols found in black tea are very strong antioxidants. The tannins in tea have a therapeutic effect on gastric and intestinal illnesses (Siemann et al., 1992).

Among tea producing countries the principal producers are China, India, Sri Lanka, Kenya and Indonesia which account for $80 \%$ of global production. India is a major producer, consumer, and exporter of tea accounting for $31 \%$ of the total global production of tea. In India, there are three different geographical areas of cultivation and production of tea. However, in India green tea accounts for only $1 \%$ of total production of tea. Since there are very few studies which document the antioxidant potential of Indian tea, an attempt is made to study total polyphenol content and antioxidant activity in different brands of tea and also the possible correlation between TPC and antioxidant activity. A very few peoples are known for their better antioxidants potential in black tea and green tea. My present study was done to estimate the total phenolic content (TPC), FRAP activity or antioxidant power and total antioxidant capacity in both black and green teas and 
investigate the better one in both and was also done the relationship between the phenolic content with the antioxidant activity of the tea samples.

\section{Materials and Methods}

We had used six different green tea samples (labeled as AF) and ten different black tea (labeled G-P) available in the local departmental stores of different brand name of the particular area of cultivation, India. Each tea sample was studied in triplicate.

\section{Preparation of extract}

The preparation of extract was done in the dept. of biochemistry laboratory, Dr. R.P.C.A.U, Samastipur, Pusa, Bihar $200 \mathrm{mg}$ of each sample was weighed, and to it, $5 \mathrm{ml}$ of $70 \%$ methanol at $70{ }^{\circ} \mathrm{C}$ was added. The extract was mixed properly and heated at 70 ${ }^{\circ} \mathrm{C}$ on a vortex for $10 \mathrm{~min}$. After cooling at room temperature, the extract was centrifuged at $2000 \mathrm{~g}$ for $10 \mathrm{~min}$. The supernatant was collected in a centrifuge tube. The extraction step was repeated twice. Both extracts were pooled, and the volume was adjusted to $10 \mathrm{ml}$ with cold $70 \%$ methanol. One milliliter of the extract was diluted with water to $100 \mathrm{ml}$. Analysis of the tea extract was done in triplicate.

\section{Determination of Total Polyphenol Content (TPC)}

The total polyphenol content of the water extract was determined by the FolinCiocallteu method (s. Toda, 2005). $0.5 \mathrm{~mL}$ tested sample was mixed with $0.5 \mathrm{~mL}$ of Folin-Ciocallteu reagent and $0.5 \mathrm{~mL}$ of $10 \%$ sodium carbonate solution. After the mixture was incubated at room temperature for $1 \mathrm{~h}$, the absorbance was measured at $760 \mathrm{~nm}$. The total polyphenol was expressed as $\mathrm{mg} / \mathrm{g}$ tannic acid equivalent.

\section{Determination of ferric ion reducing antioxidant power assay (FRAP)}

The total antioxidant power was determined by spectrophotometry, using ascorbic acid as standard, modified FRAP assay. $0.1 \mathrm{ml}$ of extract was taken, and to it, $0.9 \mathrm{ml}$ of ethanol, $5 \mathrm{ml}$ of distilled water, $1.5 \mathrm{ml}$ of $\mathrm{HCl}, 1.5 \mathrm{ml}$ of potassium ferricyanide, $0.5 \mathrm{ml}$ of $1 \% \mathrm{SDS}$ and $0.5 \mathrm{ml}$ of $0.2 \%$ of ferric chloride was added. This mixture was boiled in a water bath at $50^{\circ} \mathrm{C}$ for 20 minutes and cooled rapidly. Absorbance was measured at $700 \mathrm{~nm}$ to measure the reducing power of the tea extract. The antioxidants in samples were derived from a standard curve of ascorbic acid ranging from 10 to $100 \mu \mathrm{g} / \mathrm{mL}$. The total antioxidant power was expressed as $\mathrm{mg}$ ascorbic acid equivalent $(\mathrm{AAE}) / \mathrm{g}$

\section{Determination of Total antioxidant}

For the determination of total antioxidant capacity by using phosphomolybdenum assay, the tubes contained $0.2 \mathrm{ml}$ of extract is mixed with $1.8 \mathrm{ml}$ of distilled water, $2 \mathrm{ml}$ of phosphomolybdenum reagent $(2.8 \mathrm{mM}$ (40 $\mathrm{mg})$ of sodium phosphate and $4 \mathrm{mM}$ ammonium molybdate $(49 \mathrm{mg}$ ) in $10 \mathrm{ml}$ of 0.6 $M$ sulphuric acid). The tubes were incubated at $95^{\circ} \mathrm{C}$ for 90 minutes. The mixtures were cooled to room temperature, and absorbance was measured at $695 \mathrm{~nm}$. The antioxidant capacity was expressed as mg Ascorbic Acid Equivalent (AAE) /g.

\section{Statistical analysis}

The assays were carried out in triplicate, and the results were expressed as mean values and the standard deviation (SD). The statistical differences did by Student's t-test ( $\mathrm{p}<0.05)$. Correlations were established using Pearson's correlation coefficient $(r)$ in bivariate linear correlations using Microsoft office Excel 2007 and SPSS, version 16. 


\section{Results and Discussion}

The total polyphenol content of 10 samples of black tea and six samples of green tea were estimated. The variations in polyphenol levels in black tea (2.11- $0.26 \mathrm{mg}$ TAE/g) and green tea (5.20- $1.17 \mathrm{mg} \mathrm{TAE} / \mathrm{g}$ ) had observed in our study (Fig. 1) could be due to variations in the climate and agronomic practices and other factors such as tea types, commercial brands of tea, tea plantation area etc. The other results also supported to our study that the total polyphenol content in green tea $(3.066 \pm 1.911$ $\mathrm{mg} \mathrm{TAE} / \mathrm{g}$ ) was significantly higher than in black tea $(0.72 \pm 0.55 \mathrm{mg}$ TAE/g) $(\mathrm{p}<0.05)$ (Suteerapataranon et al., 2008). The higher levels of polyphenols in green tea (unfermented tea) than black tea could be due to the conversion of the tea polyphenols into thearubigins and theaflavin during the fermentation process (Jain, 1999). Various other studies have also reported higher total polyphenol content in green tea (Anesini et al., 2008; Shrestha et al., 2010, Nor Ohairul Izzreen and Mohd Fadzelly, 2013). In our study, the Kangra tea had higher polyphenol content than Darjeeling tea as reported by Vashisht et al., (2007) as the Kangra tea has higher amounts of epigallocatechin-3-gallate as compared to North-East Darjeeling tea. Polyphenols in tea have been reported to have a strong antioxidant property which could be attributed to various types of the flavan-3-ols present in tea. These flavan-3-cells have been reported to prevent oxidative stress by chelating free ferrous ions which are responsible for the formation of reactive oxygen species by various metabolic processes (Tsai et al., 2007).

Total Antioxidant power of 10 samples of black tea and six samples of green tea were estimated by using modified ferric ion reducing antioxidant power (FRAP) method. The results showed that the FRAP levels were significantly higher in green tea than ten samples of black tea. In black tea, the FRAP levels ranged from $(5.58 \mathrm{mg} \mathrm{AAE} / \mathrm{g}$ to 1.21 $\mathrm{mg} \mathrm{AAE} / \mathrm{g}$ ) whereas in green tea had ranged (8.88 mg AAE/g to $3.26 \mathrm{mg} \mathrm{AAE} / \mathrm{g}$ ) (Fig. 2). Our results also supported from other studies have also shown that the FRAP levels were significantly higher in green tea $(5.866 \pm 2.73$ mg AAE/g) as compared to black tea $(2.034 \pm 1.39 \mathrm{mg}$ AAE/g) $(\mathrm{p}<0.05)$ ( $\mathrm{Su}$ et al., 2007, Dutta et al., 2013). The higher the absorbance at $700 \mathrm{~nm}$ indicates the more significant the reducing power of the extract. The reducing power is associated with the presence of reductones (Duh, 1998). Reductones react with certain precursors of peroxides and prevent peroxides formation. Being good electron donor, phenolic compounds show the reducing power and ability to convert the ferric ion $\mathrm{Fe}^{+3}$ to $\mathrm{Fe}^{+2}$ ion by donating an electron. Gordon (1990) reported that the antioxidant action of reductones is based on the breaking of the free-radical chain by donating a hydrogen atom.

Total Antioxidant Capacity of 10 samples of black tea and six samples of green tea was estimated by using phosphomolybdenum assay. This assay usually detects total antioxidants such as ascorbic acid, some phenolics, $\alpha$ - tocopherol and carotenoids. In the present study, the total antioxidant capacity in green tea $(22.866 \pm 7.036 \mathrm{mg}$ $\mathrm{AAE} / \mathrm{g})$ is significantly higher than in black tea $(3.386 \pm 1.28 \mathrm{mg} \mathrm{AAE} / \mathrm{g})(\mathrm{p}<0.05)$ (Fig. 3).

Various other studies have reported higher antioxidant activity in green tea than in black tea (Yen et al., 1995; Chan et al., 2010). The higher antioxidant activity is due to potent antioxidant activities of catechins in green tea are due to their three adjacent hydroxyl $(\mathrm{OH})$ groups on the $\beta$-ring as in EGCG, GCG, EGC and GC which are more effective in scavenging free radicals than the two adjacent $\mathrm{OH}$ groups as in ECG, CG, and EC. 


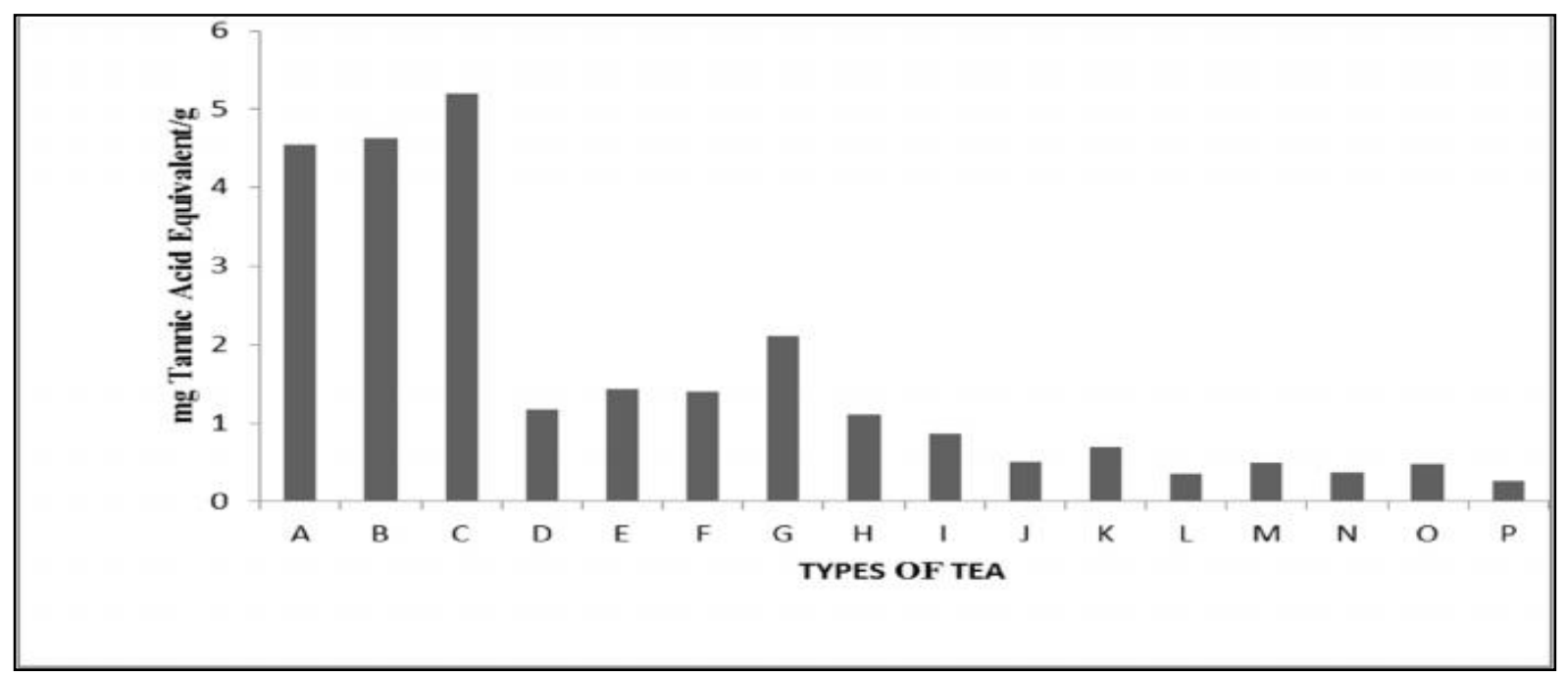

Fig.1 Total Phenolic Content of Green Tea (A to F) \& black tea (G to P)

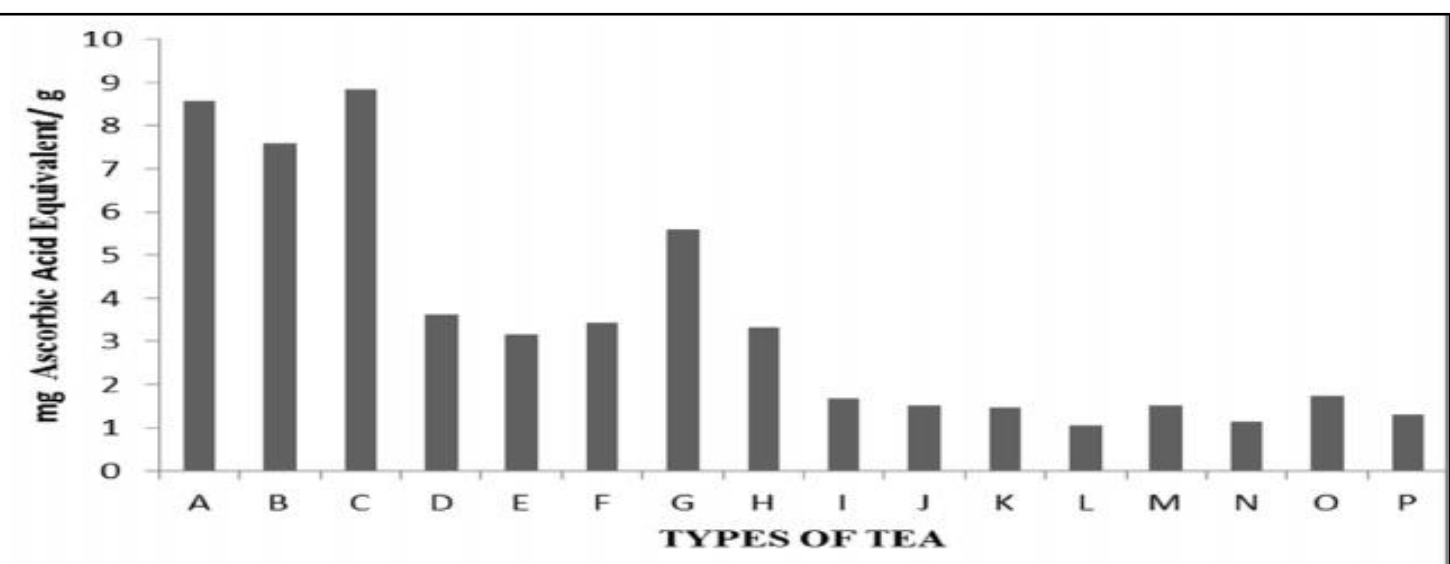

Fig.2 Total Antioxidant power of Green Tea (A to F) \& black tea (G to P) FRAP method

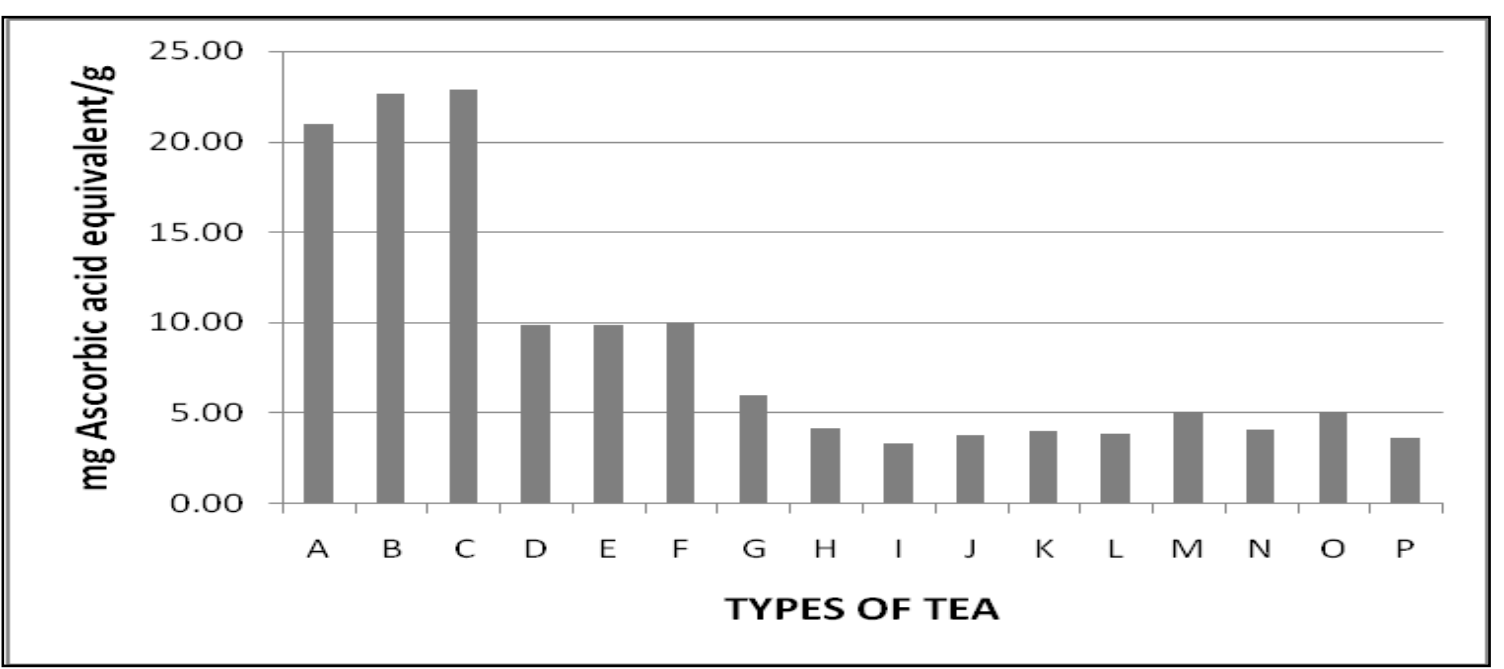

Fig.3 Total Antioxidant Capacity of Green Tea (A to F) \& black tea (G to P) 
The content of EGCG and EGC in green tea is much higher than in black tea (Almajano et $a l ., 2008)$. In case of black tea, the antioxidant properties have been attributed to its chemical components of thearubigins, phenolic acids, catechins, and theaflavins. Theaflavins which impart color, brightness, and astringency to black tea infusion also possess potent antioxidant properties (Shivaki et al., 1994; Miller et al., 1996). The total antioxidant capacity showed a strong correlation with TPC (and $r_{2}=0.9287$ ) as reported earlier by Dutta et al., (2013) implying that polyphenol possesses antioxidant property that protects against oxidative stress. The evaluation of antioxidant activity and the total polyphenol contents of the different brands of black tea and green tea available in Indian market. The antioxidant activity in Indian tea showed a strong correlation with TPC. It can be concluded that Indian tea especially green tea may act as a natural antioxidant substitute. However, furthermore studies on Indian green tea have to be done to make it a popular beverage among Indians.

\section{Acknowledgment}

The author is thankful to Department of Biochemistry, Dr. R.P.C.A.U, Pusa, for providing necessary facilities for carrying out the experimental work. We are also thankful to Mr. A.A. Daudi, HOD, Biochemistry for his support and encouragement for the fulfillment of this entire work.

\section{Conflict of Interest Disclosure}

"Hereby we are declaring that there is no conflict of interest regarding the publication of this paper."

\section{References}

Almajano, M. P., Carbó, R., Limenéz, A. L. and Gordon, M. H., 2008. Antioxidant and antimicrobial activities of tea infusions. Food Chem. 108, 55-63.

Baptista, Ja. B., Da P., Tavares J.F.P., Carvalho, R.C.B., 1999. Comparative study and partial characterization of Azorean green tea polyphenols. Journal of Food Composition and Analysis 12(4): 273-287.

Baptista, Ja. B., Tavares, J.F.P., Carvalho, R.C.B., 1998. Comparison of catechins and aromas among different green teas using HPLC/SPME-GC. Food Research International 31(10): 729-736.

Cabrera, C., Gimenez, R., Lopez, C. M., 2003. Determination of Tea Components with Antioxidant Activity. J. Agric. Food Chem. 51: 4427-4435.

Cheng, T.O., 2004. Will green tea be even better than black tea to increase coronary flow velocity reserve? American Journal of Cardiology 94(9): 1223-1223.

Duh, P.D., 1998. Antioxidant activity of Budrock (Arctium lappa Linn): Its scavenging effect on free radical and active oxygen. J. Amm. Oil Chem. Society, 75: 455-461.

Dutta, A. K., Siddiquee, M. A., Hossain, S. and Kabir, Y., 2013. Finlay green tea possesses the highest in vitro antioxidant activity among the 20 commercially available tea brands of Bangladesh. Malaysian Journal of Pharmaceutical Sciences. 11(2): 11-20.

Farhoosh, R., Golmovahhed, G. A. and Khodaparast, M. H. H., 2007. Antioxidant activity of various extracts of old tea leaves and black tea wastes (Camellia sinensis L.). Food Chemistry 100, 231 - 236.

Gordon, M.F., 1990. The mechanism of antioxidant in vitro. In: Hudson BJF (eds), Food antioxidants. Elsevier Appl. Sci. London, pp. 1-18.

Ho, C. T., Osawa, T., Huang, M. T., Rosen, R. T., 1994. Food Phytochemicals for 
Cancer Prevention II Tea Spices \& Herbs. Washington D.C. American Chemical Society.

Jain, N. K., 1999. Biosynthesis of precursors for liquor and flavor characteristics in black tea. Global advances in tea science. $\mathrm{P}$ 723- 748, Aravali books international (P) Ltd, New Delhi.

Macfarlane 2004. The Empire of Tea. p 32. The Overlook Press.

Mckay, D. L., Blumberg, J.B., 2002.The role of tea in human health: an update. Journal of the American College of Nutrition 21(1): 1-13.

Peterson, J., Druyer, J., Bhagwat, S., Haytowitz, D., Holden, J., Eldridge, AL., Beecher, G., Ala-Desamni, J., 2005. Major Flavonoids in Dry Tea. $J$. Food Compost. Anal. 18: 487-501.

Shagana, J. A., Geetha, Dr. R., 2017. Comparative Analysis of Antimicrobial Activity of Black Tea, Green Tea and White Tea Extracts on Streptococcus Mutans by Tube Dilution Method. J. Pharm. Sci. \& Res. 9(9): 1581-1582.

Shivaki, M., Hava, Y., Osawa, T., Kumon, H., Nakayama, T. and Kawakishi, S., 1994. Antioxidative and antimutagenic effects of theaflavins from black tea. Mutat Res 323, 29-34.

Siemann, E. H., and Creasy, L. L., 1992. J Enol. Vitic 43, 49

Su, X., Duan, J., Jiang, Y., Duan, X. and Chen, F., 2007. Polyphenol Profile and Antioxidant Activity of Brewed Oolong Tea at Different Conditions. Int. J. Mol. Sci. 8, 1196-1205.

Suteerapataranon, S. and Pudta, D., 2008.
Flow Injection AnalysisSpectrophotometry for Rapid Determination of Total Polyphenols in Tea Extracts. J. of Flow Injection Analysis 25, 61-64.

Toda, S., 2005. Antioxidative Effects of Polyphenols in Leaves of Houttuynia Cordata on Protein Fragmentation by Copper-Hydrogen Peroxide in vitro, Journal of Medicinal Food, 8(2): pp. 266-268.

Tsai, P. J., Tsai, T. H., Yu, C. H. and Ho, S. C., 2007. Comparison of NOscavenging and NO-suppressing activities of different herbal teas with those of green tea. Food Chemistry 103, $181-187$.

Vasisht, K., Sharma, P. D. and Karan, M., 2007. Study to Promote the Industrial Exploitation of Green tea Polyphenols in India. ICS-UNIDO.

Vinson, J. A., 2000. Black and green tea and heart disease: a review. BioFactors 13(1-4): 127-132.

Wang, H. and Helliwell, K., 2001. Determination of flavonols in green and black tea leaves and green tea infusions by high-performance liquid chromatography. Food Research International 34, 223 - 227.

Wheeler, D. S., Wheeler, W. J., 2004. The medicinal chemistry of tea. Drug Development Research 61(2): 45-65.

Yen, G. C. and Chen, H. Y., 1995. Antioxidant activity of various tea extracts in relation to their antimutagenicity. J Agric. Food Chem. $43,27-32$.

\section{How to cite this article:}

Kiran and Pradeep Kumar. 2018. Study of Antioxidant Properties in Black Tea and Green Tea. Int.J.Curr.Microbiol.App.Sci. 7(05): 1163-1169. doi: https://doi.org/10.20546/ijcmas.2018.705.141 